\title{
Happiness, Willingness-to-Share and Materialism in the Experiential Purchase
}

\author{
I-Ling Ling, Yi-Fen Liu, and Edwin Rajah
}

\begin{abstract}
This research investigates how people experience happiness via experiential purchases and explains the mechanisms of how willingness-to-share, materialism and life satisfaction affect happiness. Interpersonal communication is important. As consumers often tell others about their travel experiences (e.g. hotels, attractions or restaurants), do the "talkable" characteristics of tourism make a difference in advancing happiness? Prior research has shown that higher well-being is associated with spending less time alone and more time talking to others. By using naturalistic observation, this research shows that happy and unhappy people differ in the amount of small talk and substantive conversations they participate in. By measuring the extent to which consumers are willing to share their purchase information with others, we provide insight into why tourism provides more happiness through experiential rather than material purchases.

Two studies which asked people to recall or imagine happy tourism experiences revealed a meaningful distinction between experiential and material purchases. The results of Study 1 show that people's higher willingness-to-share share their experiences explains why experiential purchases elicit greater happiness than material purchases. That experiential purchases elicit greater happiness than material purchases is demonstrated by people's higher willingness to share their experiences (Study 1). For individuals who are high in materialism, the effect of experiential purchases on greater happiness is reduced. The results of Study 2 reveal that consumers gain more happiness by participating in non-commission-based package tours than in commission-based package tours. For individuals who have high life satisfaction, the effect is reduced. Together, these findings help better understand the interplay across experiential (vs. material) purchases, materialism, and life satisfaction in advancing tourism happiness.
\end{abstract}

\footnotetext{
I.-L. Ling $(\square)$

National Chiayi University, Chiayi City, Taiwan

e-mail: yiling@mail.ncyu.edu.tw

Y.-F. Liu

National Kaohsiung First University of Science and Technology, Kaohsiung City, Taiwan e-mail: yifenliu@nkfust.edu.tw

E. Rajah

Auckland University of Technology, Auckland, New Zealand

e-mail: erajah@aut.ac.nz
} 